\title{
Supercapacitor/Battery hybrid Powered Electric Bicycle via a Smart Boost Converter
}

\author{
Manoj.E, Dino Isa, Roselina Arelhi \\ Department of Electrical \& Electronic Engineering, University of Nottingham Malaysia, Jalan Broga, 43500 Semenyih, \\ Selangor Darul Ehsan, Malaysia. \\ keyx9mem@nottingham.edu.my,Dino.Isa@nottingham.edu.my Roselina.Arelhi@nottingham.edu.my)
}

\begin{abstract}
This work implements a smart boost converter to enable an electric bicycle to be powered by a battery/supercapacitor hybrid combination. A $36 \mathrm{~V}, 250 \mathrm{~W}$ front hub motor was retrofitted onto a normal geared bike powered by a $36 \mathrm{~V} ; 12 \mathrm{Ah}$ lithium ion phosphate battery pack. A $16.2 \mathrm{~V}, 58 \mathrm{~F}$ supercapacitor module was connected in parallel to the battery pack via a custom made microcontroller-based boost converter which arbitrates power between the battery and supercapacitor. The control algorithm for the boost converter was developed using a practical approach by using various sensor inputs (battery/supercapacitor current and voltage, bike speed) and comparing the robustness of control scheme. Also energy efficient components were used in designing the boost converter to ensure maximum power transfer efficiency.
\end{abstract}

Based on the implemented system experimental results show an improvement in the up-hill acceleration of the bicycle as a direct result of the boost converter being responsive enough to harvest the extra current from the high power complementary supercapacitor module avoiding deep discharges from the battery. This enhanced battery life. The maximum speed remained unchanged while the improvement in range per charge was subjective to the terrain i.e. flat land; not significant improvement, hilly terrain; significant. However, recharging the supercapacitor via regenerative braking proved to be an arduous task since the boost converter was not designed to be bi-directional. Copyright Form of EVS25.

Keywords—Electric Bicycle, Supercapacitor, Boost Converter, Energy Management Algorithm

\section{Introduction}

For much of the world; especially places like China, India, and Sweden etc. bicycles have been a transportation mainstay because the work place and housing areas in most of these densely populated cities are within walking or cycling distance. This reliable yet overlooked form of transportation has evolved over the years from simple utility bicycles to powerful geared mountain bikes and now electric assisted bicycles or pedelecs. Environmental concerns in terms of emissions and depleting fuel reserves has revived the electric vehicle industry and research community. China has produced 21 million of bicycles within nine years (1997-2005). In 2005 itself, China has produced 10 million of bicycles [1]. Electric assisted bicycles still retain the characteristics of a conventional bicycle with an added advantage of extra power, say when riding up a hill. This enables the elderly or not so physically fit people to still enjoy riding a bicycle up a slope.

Batteries are the weak leak at the moment for any electrically propelled vehicle including the bicycle. The lack of a single reasonably priced energy storage device that can simultaneously provide high power density and high energy density has been the main stumbling block to the acceptance of electric propulsion as the main form of private and public transportation. Presently the only viable solution to this problem is to combine a high energy storage device such as an electrochemical battery or fuel cell with a high power device such as an Electric Double Layer Capacitor (EDLC) or ultracapacitor or more often 
called a supercapacitor [2]. Usually, some form of dc to dc converter executing an energy management control algorithm is used to interface the battery bank and supercapacitor array to the load bus. It is the aim of this project to design a smart boost converter with a heuristic based energy management algorithm which will optimize the power flow from the battery pack to the load.

As the name implies, a supercapacitor is a capacitor with capacitance greater than any other, usually in excess of up to 4000 Farad. Supercapacitors do not have a traditional dielectric material like ceramic, polymer films or aluminum oxide to separate the electrodes instead a physical barrier made of activated carbon. A double electric field which is generated when charged, acts a dielectric. The surface area of the activated carbon is large thus allowing for the absorption of large amount of ions [3].

\section{Advantages of Supercapacitors}

- $\quad$ Cell voltage determined by the circuit application not limited by cell chemistry

- Very high cell voltages possible

- High power density

- Can withstand extreme temperatures

- $\quad$ Simple charging methods

- Very fast charge and discharge

- Overcharging not possible

- Long life cycle

- Low impedance

Disadvantages/Shortcomings

- $\quad$ Linear discharge voltage characteristic prevents use in some applications

- Power only available for very short duration (short bursts of power)

- Low capacity

- Low energy density

- Voltage balancing required when banking

- $\quad$ High self discharge rate

Despite the fact that Lithium-ion batteries are the superior most power sources as compared to other battery systems, the performance of the Li-ion battery is greatly affected when utilized under high current discharges. Lithium ion batteries have a high energy density of about $105 \mathrm{~J} / \mathrm{kg}$; however the power density is only around $100 \mathrm{~W} / \mathrm{kg}$. As a result, the Li-ion battery cannot yield to high power demands. The addition of super capacitors in parallel to the battery can greatly augment the utilization of the battery especially at higher rates of discharge because of the high power density of super capacitors $(\sim 106 \mathrm{~W} / \mathrm{kg})$. So during high power demands, the supercapacitor aids in supplying the power instantly while it gets recharged by the battery and thus the run time of the battery super capacitor hybrid is increased and higher utilization can be ensured.

Li-ion and supercapacitors are at opposite ends of the spectrum i.e. high energy density and high power density respectively. A combination of both technologies could bring about very desirable effects in terms of battery features. A Direct connection of the supercapacitor across the battery terminals does reduce transient currents in and out of the battery. However, the best way to utilize the supercapacitor bank is to be able control its energy content through a power converter [4]. Usually, a static bidirectional buck-boost converter is used to interface the supercapacitor bank (connected to the boost side) with the battery pack (connected to the buck side) because batteries work at relatively constant voltage levels while capacitors voltage is directly related to its state-of-charge [5].

\subsection{Outline}

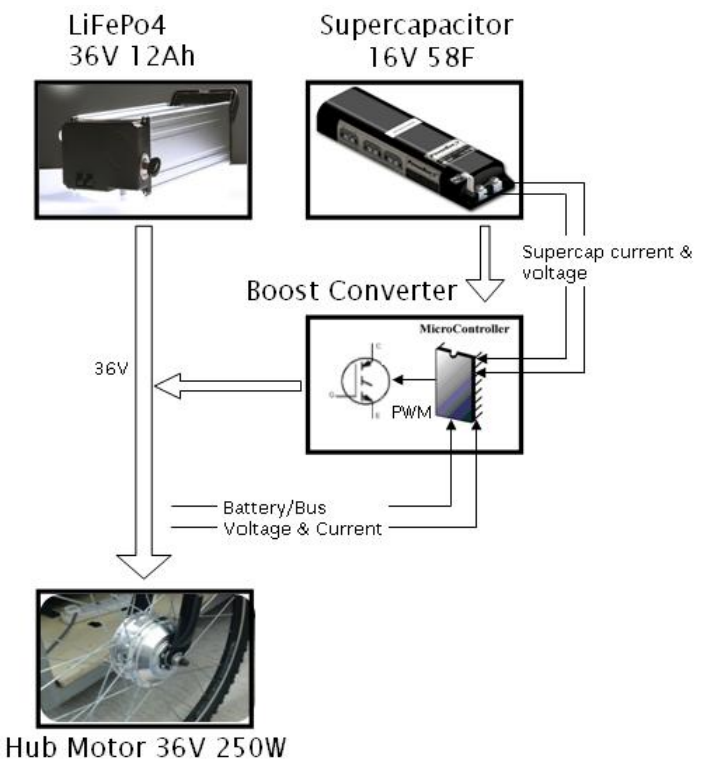

Figure 1: Overview of the proposed system

The objective of this project is to design and build a Pulse Width Modulated (PWM) DC/DC boost converter with the following ideal specifications:

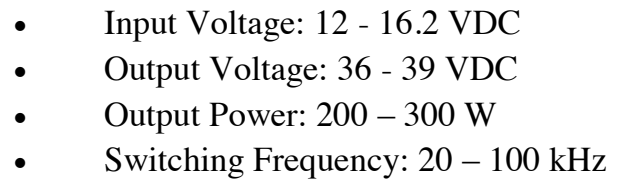

Figure 1 above shows the block diagram of the proposed system. The main power source consists of a $36 \mathrm{~V} \sim 40 \mathrm{~V}$, 12Ah lithium ion Phosphate (LiFePo4) battery pack with cell balancing circuitry which weighs $5.5 \mathrm{~kg}$. This can comfortably provide a continuous discharge current of 12A. The supercapacitor consists of a $0.5 \mathrm{~kg}$ POWERBUSRT (C) $16 \mathrm{~V}, 58 \mathrm{~F}$ module to be connected in 
parallel with the battery pack via a boost converter which is designed to harvest the maximum energy from it. The propulsion device consists of a state of the art front hub motor rated at $250 \mathrm{~W}$, eliminating the need for transmission and the losses associated with it.

Section 2 describes the sizing and design of the boost converter based on the specific energy requirements of the previously mentioned electric assisted bicycle. Section 3 discusses the results obtained from the implemented system using a portable datalogger.

\section{Boost Converter Design}

In order to size the boost converter appropriately, the electric bicycle was powered with the $36 \mathrm{~V} 12 \mathrm{Ah} \mathrm{LiFePo} 4$ batteries initially, and certain figures were collected. The track used was a mixture of flat terrain, uphills and downhills. This is shown in the table below.

\begin{tabular}{|l|l|}
\hline Maximum Voltage & $40.69 \mathrm{~V}$ \\
\hline Maximum Current & $18.38 \mathrm{~A}$ \\
\hline Average Voltage & $39.0 \mathrm{~V}$ \\
\hline Average Current & $8.2 \mathrm{~A}$ \\
\hline Max. Voltage Drop & $3.31 \mathrm{~V}$ \\
\hline Maximum Power & $693.0 \mathrm{~W}$ \\
\hline Average Power & $315.0 \mathrm{~W}$ \\
\hline
\end{tabular}
Table 1: E-bike performance with battery only

From the table above, the maximum voltage is $40.69 \mathrm{~V}$. This voltage is actually equivalent to the total batteries voltage at full charge. Even though the datasheet mentions that each battery is only supplied $36 \mathrm{~V}$, however there is some tolerance in battery which causes each battery to go up to $40 \mathrm{~V}$. When the motor is running at maximum load (i.e. uphill), the maximum current drawn from the battery is $18.38 \mathrm{~A}$ whereas when the motor is running at constant load (usually on a flat terrain) the average current is $8.2 \mathrm{~A}$. Thus, the supercapacitor is required to supply at least $10.18 \mathrm{~A}$ to ensure that batteries only supplied average current.

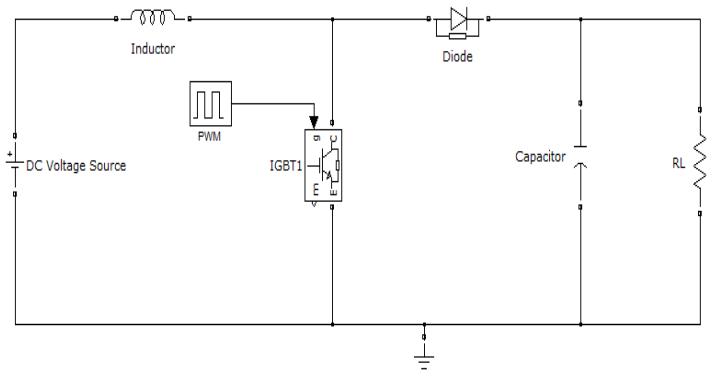

Figure 2: Conventional PWM Boost Converter

The conventional boost converter is shown in figure 2 above. It can be operated in two modes which are continuous current mode (CCM) and discontinuous current mode (DCM. This converter functions based on pulse width modulation (PWM); PWM is sent from a microcontroller/driver in order to control the IGBT to switch on or switch off.

During on time, IGBT will be turned on by setting the PWM to high. During the on time, current from the voltage source will flow through inductor and IGBT. This results in positive voltage across the inductor, thus inductor current is linearly increases. The capacitor will discharge through the load resistance in order to provide continuous supply to the load.

During off time, current through the inductor cannot change instantaneously. It will try to oppose any drop in current by reversing its electromotive force (EMF) or polarity. Thus, the inductor will be treated as another voltage source which is in series with the input voltage. Energy stored in the inductor will add extra voltage to the input voltage. The current will flow into the capacitor to charge up the capacitor as well. In short, output voltage will be boosted with extra voltage from the inductor.

\subsection{Supercapacitor Energy Analysis}

$$
\begin{aligned}
& \text { Total Energy } E_{T}=\frac{1}{2} C V^{2} \\
& E_{T}=\frac{1}{2} \times 58 \times 16^{2}=7.424 K J(2.1 \mathrm{Wh})
\end{aligned}
$$

Assume the minimum voltage can drop to $10 \mathrm{~V}$, maximum voltage is $16 \mathrm{~V}$

$$
\begin{gathered}
\text { Usable Energy; } \mathrm{E}_{\mathrm{u}}=\left(1-\frac{V^{2} \min }{V^{2} \max }\right) E_{T} \\
\mathrm{E}_{\mathrm{u}}=4.524 \mathrm{KJ}(1.26 \mathrm{Wh})
\end{gathered}
$$

Thus 452.4W (28.28A @ 16V) can be supplied for a period of 10seconds or 226.2W (14.14A @ 16V) for 20 seconds. This is more than sufficient for an uphill acceleration keeping in mind that the battery is able to supply an average power. However the boost converter is required to output a voltage of between $38 \mathrm{~V} \sim 40 \mathrm{~V}$ depending on the battery pack voltage leading to a lower output current.

$$
\begin{aligned}
& \text { Assuming a } 90 \% \text { converter efficiency, } \\
& P_{\text {output }}=0.9 P_{\text {input }} \\
& 0.9 * V_{\text {input }} * \mathrm{I}_{\text {input }}=V_{\text {output }} * \mathrm{I}_{\text {output }} \\
& \mathrm{I}_{\text {output }}=12.89 \mathrm{~A} @ \mathrm{~V}_{\text {input }}=16 \mathrm{~V} \\
& \mathrm{I}_{\text {output }}=8.06 \mathrm{~A} @ \mathrm{~V}_{\text {input }}=10 \mathrm{~V}
\end{aligned}
$$

\subsection{Component Sizing}

The converter must be designed such that it is able to handle the worst case scenario. Thus, input voltage used in the design calculation will be the minimum whereas the output voltage will be the maximum. The design specifications are showed as below:

$$
f=100 \mathrm{kHz} \quad \text { (Arbitrarily chosen) }
$$

Duty cycle can be calculated by using the formula as follows: 


$$
\begin{aligned}
D=1-\frac{V_{\text {in }}}{V_{\text {out }}} & \\
D & =1-\frac{10}{41} \\
D & =0.756
\end{aligned}
$$

Since the output power is $500 \mathrm{~W}$ and voltage is $39 \mathrm{~V}$, the resistive load can be calculated as

$$
\begin{gathered}
R=\frac{V^{2}}{P} \\
R=\frac{39^{2}}{500}=3.042 \Omega
\end{gathered}
$$

Therefore, the minimum inductor value can be calculated by substitute the value as followed:

$$
\begin{gathered}
L_{\text {min }}=\frac{D(1-D)^{2} R}{2 f} \\
L_{\text {min }}=\frac{0.756 \times(1-0.756)^{2} \times 3.042}{2 \times 100 \times 10^{3}} \\
L_{\text {min }}=0.6846 \mu H
\end{gathered}
$$

The inductor must be selected such that it is able to handle input current. The converter is assumed to be $90 \%$ efficient, thus the output power will be nine-tenth of the input power.

$$
I_{\text {in }}=\frac{P_{\text {out }}}{0.9 V_{\text {in }}}=14.25 \mathrm{~A}
$$

The selected inductor is J. Bournes and Miller 8121-RC which has $1 \mathrm{mH}$ inductance with maximum current of $20 \mathrm{~A}$. The output capacitance reduces the output ripple voltage. The filtering capacitance is selected by assuming the ripple voltage, $\Delta V_{\text {out }}$ is equaled to $10 \%$ of the output voltage.

$$
\begin{gathered}
C_{\text {min }}=\frac{1}{\Delta V_{o}} \times \frac{V_{o}}{R} \times D T \\
C_{\text {min }}=\frac{1}{0.05 \times 39} \times \frac{39}{3.042} \times 0.756 \times \frac{1}{100 \times 10^{3}} \\
C_{\text {min }}=50 \mu \mathrm{F}
\end{gathered}
$$

The selected output capacitance is $100 \mu \mathrm{H}$. Capacitors with

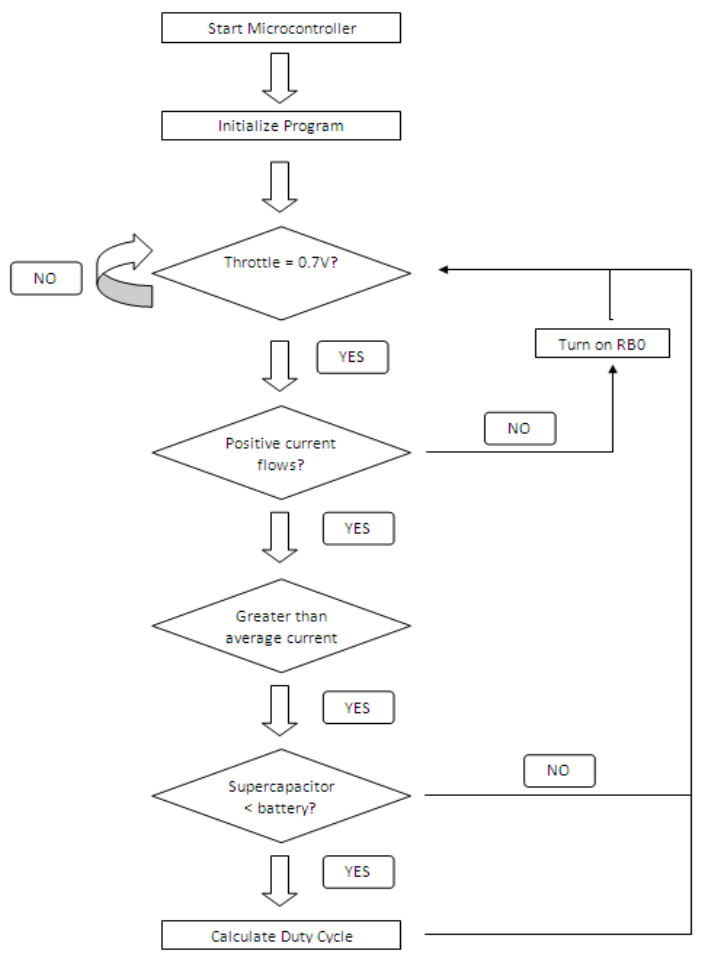

higher capacitance will actually reduce the ripple voltage, but higher capacitance will have a slower response time [6]. The table below shows the list of other components used in this design.

\begin{tabular}{|c|l|l|}
\hline & Component & Function \\
\hline 1 & $\begin{array}{l}\text { PIC16F877A } \\
\text { Microcontroller }\end{array}$ & $\begin{array}{l}\text { Generate } \\
\text { signals based on input } \\
\text { sensors }\end{array}$ \\
\hline 2 & $\begin{array}{l}\text { HCPL 3120 } \\
\text { Optocoupler }\end{array}$ & $\begin{array}{l}\text { Gate driver for } \\
\text { switching device }\end{array}$ \\
\hline 3 & $\begin{array}{l}\text { IKP15N60T IGBT } \\
\text { 20A) }\end{array}$ & $\begin{array}{l}\text { Switching device for } \\
\text { converter }\end{array}$ \\
\hline 4 & $\begin{array}{l}\text { Vishay Schottky diode } \\
\text { 30A) }\end{array}$ & $\begin{array}{l}\text { Prevent reverse } \\
\text { current }\end{array}$ \\
\hline 5 & $\begin{array}{l}\text { LTS-25NP LEM current } \\
\text { sensor }\end{array}$ & $\begin{array}{l}\text { Sense load current } \\
\text { give input to MCU }\end{array}$ \\
\hline
\end{tabular}

Table 2: Components for boost converter

\subsection{Control Algorithm}

Figure 3 above describes the simple control strategy adopted for calculating the duty cycle of the PWM pulse which is required to turn on the IGBT for the boost converter. Inputs from a Hall Effect speed sensor and current sensors are required to turn on the converter. This ensures that the E-bike is on and ready for an impending acceleration and also prevents unnecessary usage of the supercapacitor's limited energy. Voltage divider circuits at the input side (supercapacitor) and output side (battery/converter out) feed input signals to the microcontroller. By comparing these two signals, the duty cycle can be appropriately adjusted.

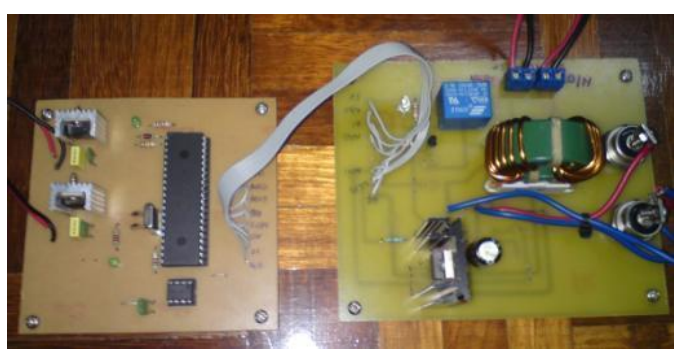

Figure 4: Boost Converter with control circuit.

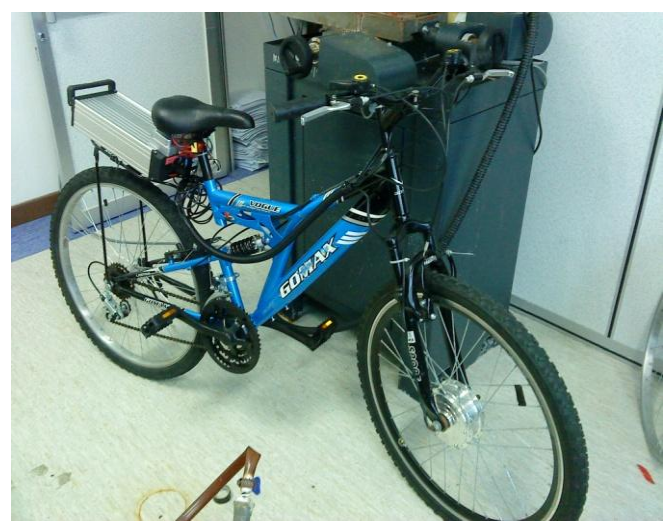

Figure 5: Ebike with battery supercapacitor hybrid via a boost converter. 


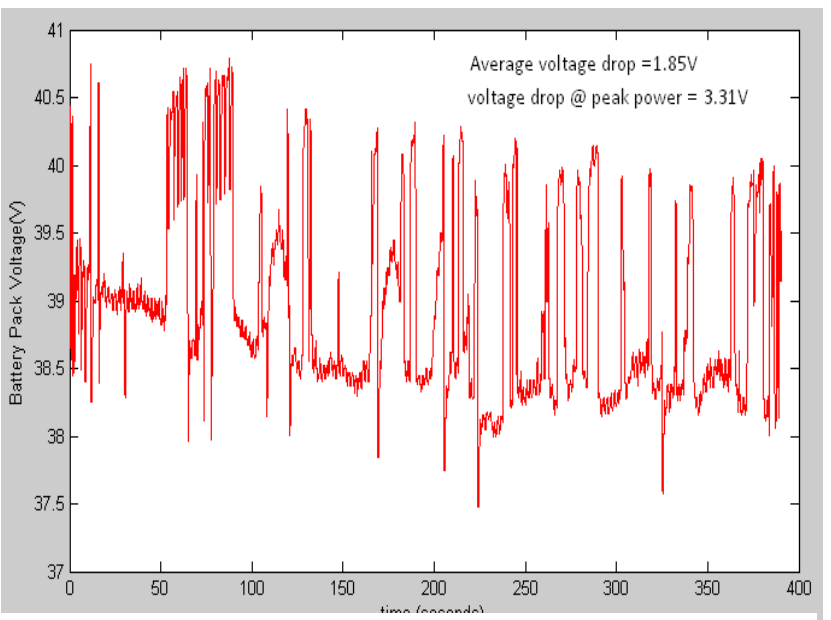

Figure 6: Battery pack voltage of E-bike with only LiFePo4 as power source

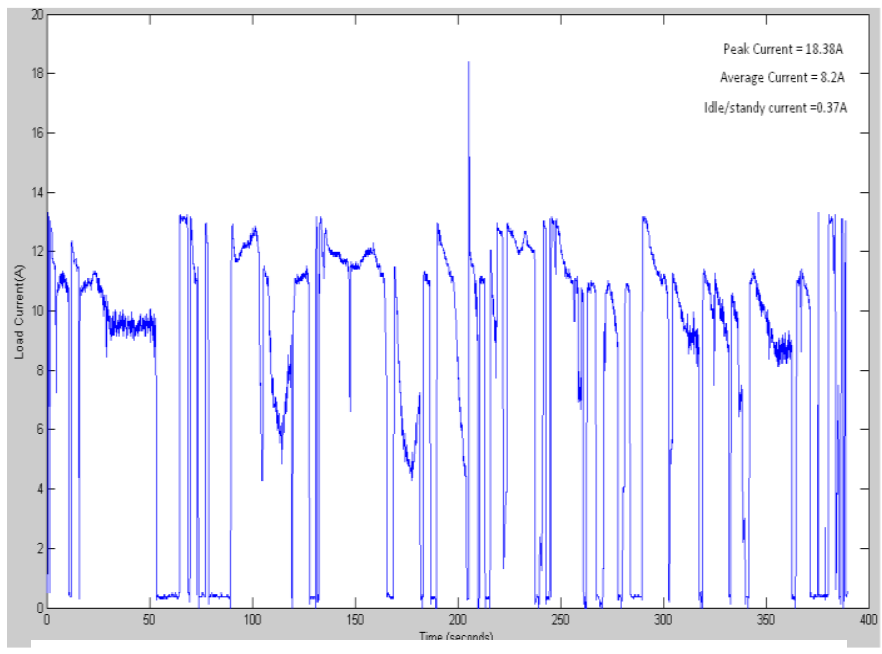

Figure 7: Current drawn from LiFePo4 only

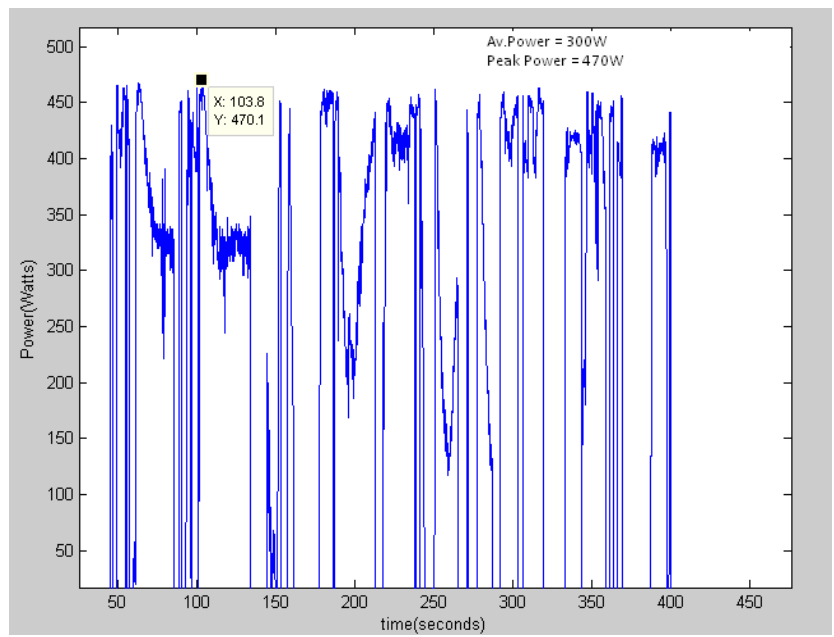

Figure 8: Power Output from LiFePo4 battery

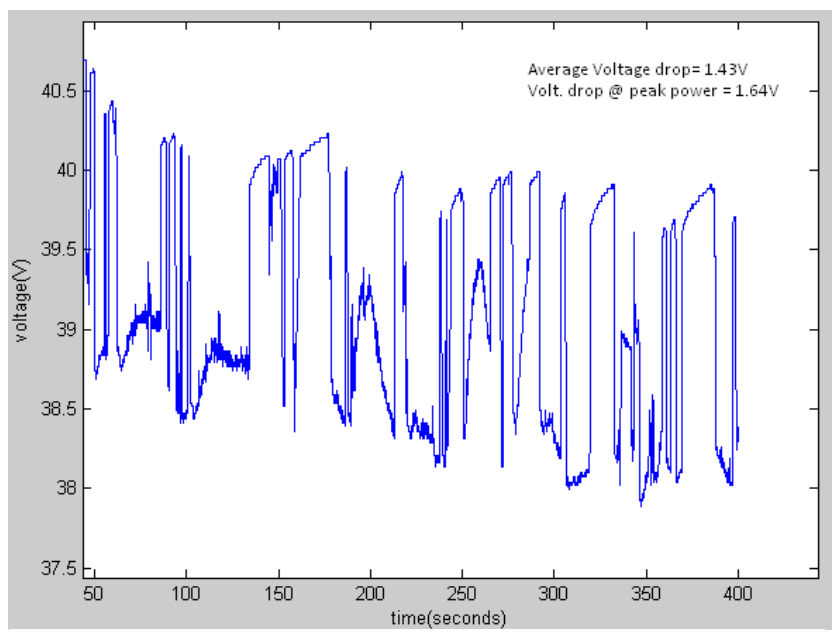

Figure 9: Battery pack voltage of E-bike with hybrid power source

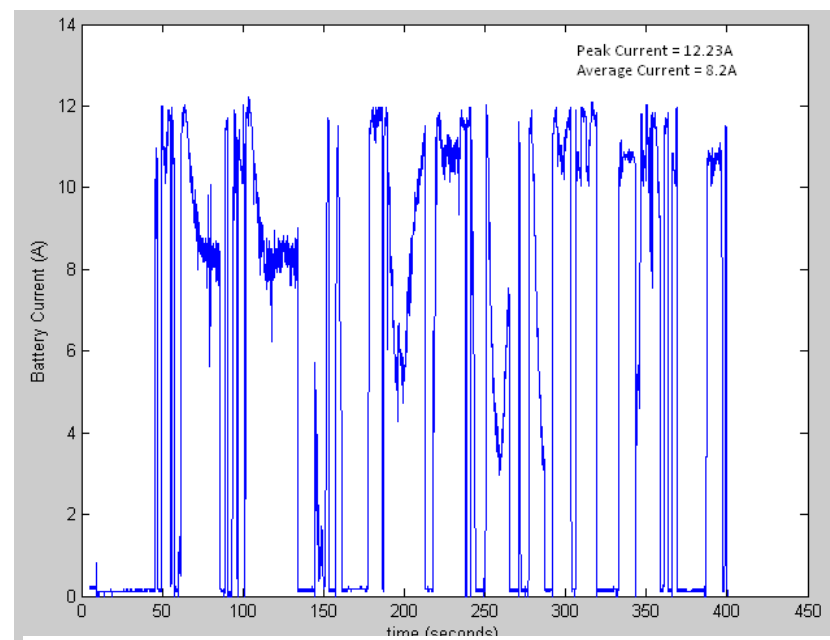

Figure 10: Current drawn from LiFePo4 battery with hybrid power source

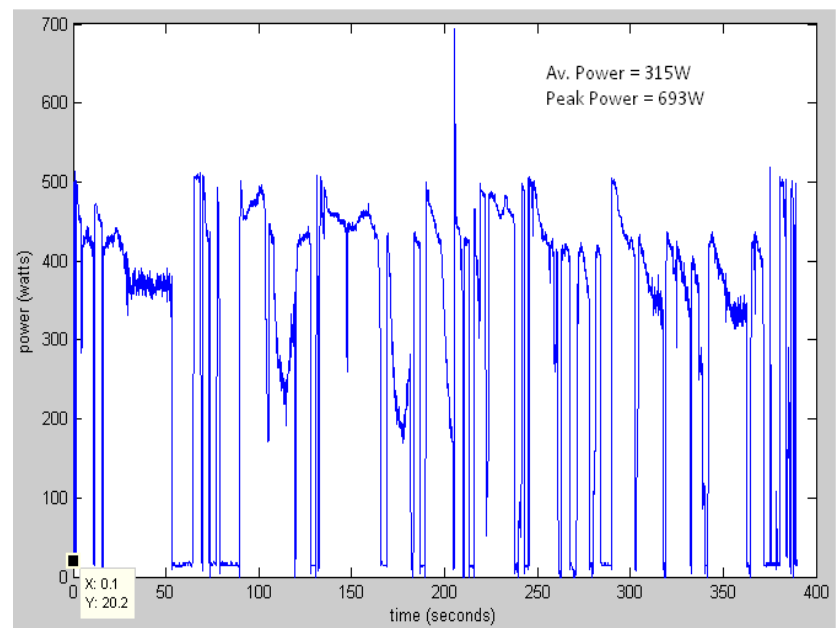

Figure 11: Power Output from LiFePo4 battery with hybrid power source 


\section{Results and Discussion}

A portable data logging device was used to collect sensor data of bike speed, battery voltage and current, supercapacitor voltage and current. This was used to evaluate the performance of the electric assisted bicycle in terms of maximum speed, voltage drop of battery pack, peak current drawn from battery pack and up-hill acceleration.

Figure 6 to figure 8 shows the battery parameters when the E-bike was powered solely by the battery pack. An average voltage drop of $1.85 \mathrm{~V}$ was recorded while riding on flat terrain while a maximum voltage drop of $3.31 \mathrm{~V}$ was recorded when riding uphill. A peak current of 18.38A was recorded uphill. This is potentially dangerous for the battery as it only able to handle a maximum of $15 \mathrm{~A}$ continuous discharge. An Average Power of $315 \mathrm{~W}$ and peak of $693 \mathrm{~W}$ was subsequently recorded.

Figure 9 to figure 11 plots the battery parameters when the E-bike was powered by hybrid battery/supercapacitor power source. A significant reduction in the maximum voltage drop from $3.31 \mathrm{~V}$ to $1.64 \mathrm{~V}$ occurred. This was a direct result of the supercapacitor being able to attend to the peak power requests from the load. Peak current from the battery pack reduced to $12.23 \mathrm{~A}$ which was observed in figure 10 . As a result, peak power reduced to $470 \mathrm{~W}$. Table 3 below summarizes the results.

For every instance in time, the current drawn from the battery-only power source is always greater than the current drawn from the battery + supercapacitor power source. However, there appears to be certain discrepancies which is caused by variation in driving pattern although data collection for both instances where taken by following exactly the same route. The voltage profile of the hybrid power source is smoother with less variations than the profile of the battery only power source. Since the voltage of the supercapacitor is always tied to the battery pack (direct parallel connection), we cannot fully unravel its true potential which is its ability to charge and discharge very fast. A simple efficiency analysis shows that only $23 \%$ of the total energy of the supercapacitor was used up. The remaining $77 \%$ cannot be utilized due to the direct parallel configuration.

This test was just part of comprehensive tests that was scheduled to be carried out in near future to optimize supercapacitor integration with the electric vehicle. Significant amount of engineering work still remains for the optimization especially the "smart" control algorithm for the supercapacitor to be switched "on" and "off" at most appropriate driving pattern. This would enable a wider range of usage of the supercapacitor's energy of up to $75 \%$.

\begin{tabular}{|l|l|l|}
\hline $\begin{array}{l}\text { Battery Parameter } \\
\text { @ Peak conditions }\end{array}$ & $\begin{array}{l}\text { LiFePo4 } \\
\text { only }\end{array}$ & $\begin{array}{l}\text { LiFePo4 } \\
\text { Supercap }\end{array}$ \\
\hline Volt. Drop & $3.31 \mathrm{~V}$ & $1.64 \mathrm{~V}$ \\
\hline Current & $18.38 \mathrm{~A}$ & $12.23 \mathrm{~A}$ \\
\hline Power & $693 \mathrm{~W}$ & $470 \mathrm{~W}$ \\
\hline $\begin{array}{l}\text { Max Speed from GPS } \\
\text { Speed sensor }\end{array}$ & $28 \mathrm{Kmh}$ & $28.8 \mathrm{Kmh}$ \\
\hline
\end{tabular}

Table 3: Summary of Results

The parallel hybrid power source has no significant effect on the maximum speed achievable over a drive cycle except that the rider felt an improvement in uphill acceleration as compared to battery alone.

\section{Conclusion}

In conclusion, this work has successfully implemented a battery/supercapacitor hybrid power source for an electric assisted bicycle using state of the art hub motor technology. A boost converter was designed and implemented based on the energy requirements of the system.

Based on the implemented system experimental results show an improvement in the up-hill acceleration of the bicycle as a direct result of the boost converter being responsive enough to harvest the extra current from the high power complementary supercapacitor module avoiding deep discharges from the battery. This enhanced battery life. The maximum speed remained unchanged. The main battery pack was shielded from high discharge currents which would eventually enhance its life cycle.

\section{References}

[1] Alan. A Parker, Electric Power-Assisted Bicycles Reduce Oil Dependence and Enhance the Mobility of the Elderly electric power assisted bicycle. Presented at 29th Australian Transport Research Forum.

[2] Don Tuite ,"Get the Lowdown on Ultracapacitors", Technology report electronic design online , November 2007. URL:

http://electronicdesign.com/Articles/ArticleID/17465/17465.html. [3] Adrian Schneuwly, Bobby Maher, Juergen Auer. "Ultracapacitors, the New Thinking in the Automotive World". Maxwell Technologies Inc.

[4] Pay, S.; Baghzouz, Y.; , "Effectiveness of batterysupercapacitor combination in electric vehicles," Power Tech Conference Proceedings, 2003 IEEE Bologna , vol.3, no., pp. 6 pp. Vol.3, 23-26 June 2003

[5] Dixon, J.W.; Ortuzar, M.E.; "Ultracapacitors + DC-DC converters in regenerative braking system," Aerospace and Electronic Systems Magazine, IEEE , vol.17, no.8, pp. 16- 21, Aug 2002

[6] A.Paymen and S.Oierfederici (2007), Energy control of supercapacitor/fuel cell hybrid power source. Energy Conversion Management 49(2008) 1637-1644 
[7] H.Farzanehfard and D.S Beyragh (2007), A Bidirectional soft switched ultracapacitor interface circuit for hybrid electric vehicles. Energy Conversion Management 49(2008) 3578-3584.

[8] Michael George and Sam Choi (2003), Contrasting Hybrid Electric Bicycles and Electric Bicycle. Inter-Professional Project 315 Spring 2003 p20-25.

[9] Golden motor (2008), Testing Report, Last retrieved: http://www.goldenmotor.com/hubmotors/Mini\%20Front\%2036V 200W\%20Performance.pdf on 8 March 2010.

[10] Farnell, EPCOS - B82506W0000A007 - CHOKE, I CORE, $0.2 \mathrm{MH}$, $40 \mathrm{~A}, \quad$ Last retrieved: http://my.farnell.com/epcos/b82506w0000a007/choke-i-core-02mh-40a/dp/1644743 on 10 March 2010.

[11] Farnell, BOURNS JW MILLER - 8121-RC - INDUCTOR, COMMON MODE, $1 M H$, Last retrieved:

http://my.farnell.com/bourns-jw-miller/8121-rc/inductorcommon-mode-1mh/dp/1692691 on 10 March 2010.

[12]C.Blake and C.Bull, IGBT or MOSFET: Choose Wisely. Last Retrieved: http://www.irf.com/technicalinfo/whitepaper/choosewisely.pdf on 22 Sept 2009.

[13]W. A Giovino(2002),Microcontrollers and DSPs-Will the Two World Intersects? Last Retrieved: http://www.microcontroller.com/Embedded.asp?did=61 on 24 Sept 2009.

[14] Rüdiger Bürkel and Michel Friot (1997), ASIC Based CloseLoop Transducers from 6A to 25A Nominal, Last Retrieved: http://pccorot15.obspm.fr/COROT-ETC/Files/lts.pdf on 16 March 2010.

[15]Wikipedia, Schottky Diode, Last Retrieved: http://en.wikipedia.org/wiki/Schottky_diode on 16 March 2010.

[16]Croydon Cycling Campaign (2008), Electric-Assist Cycles, Last retrieved: http://www.croydon-lcc.org.uk/info/electric.htm on 13 March 2010.

\section{Authors}

\section{Manoj Embrandiri}

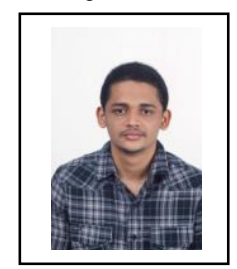

PhD Student

Department of Electrical \& Electronics,

University of Nottingham, Malaysia

Jalan Broga Semenyih,

43500 Selangor Malaysia.

Tel:+60389248601 Fax: (603)89248117

Email:keyx9mem@nottingham.edu.my Manoj is currently a PhD student at the

University of Nottingham Malaysia Campus. His current interests include renewable energy systems, application of supercapacitors in electric vehicles and applied artificial intelligence methods in EV domain.

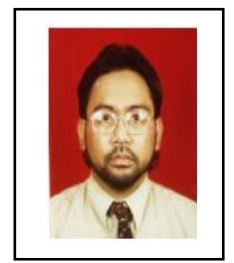

Professor Dino Isa

Professor

Department of Electrical \& Electronics, University of Nottingham, Malaysia Jalan Broga Semenyih,

43500 Selangor Malaysia.

Tel:+60389248116 Fax: (603)89248117 Email:Dino.Isa@nottingham.edu.my

His current interest is in applying the support vector machine in various domains in order to further understand its mechanisms. Prof. Isa obtained his BSEE (Hons) in Electrical Engineering from the University of Tennessee, Knoxville in 1986 and his $\mathrm{PhD}$ from the University of Nottingham, University Park,

Nottingham, England in 1991. He was employed in Motorola
Seremban as Engineering Section Head after he completed his $\mathrm{PhD}$, and moved to Crystal Clear Technology in 1996 as Chief Technology Officer prior to joining the University of Nottingham in 2001 . 